\title{
ChemComm
}

FEATURE ARTICLE

\section{Asymmetric Cross-Coupling of Alkyl, Alkenyl and (Hetero)Aryl Nucleophiles with Racemic Allyl Halides}

Received 00th January 20xx, Accepted 00th January 20xx

DOI: $10.1039 / x 0 x \times 00000 x$

www.rsc.org/

\begin{abstract}
Philipp Schäfer, Mireia Sidera, Thomas Palacin and Stephen P. Fletcher
Single enantiomer molecules are important for the pharmaceutical and agrochemical industries and increasingly so in materials science. Most strategies to obtain enantiomerically enriched molecules rely on either generating new stereogenic centres from prochiral substrates or resolving racemic mixtures of enantiomers. Dynamic asymmetric processes are poweful methods that use racemic mixtures of chiral substrates as starting material. This Feature Article focuses on asymmetric additions to racemic substrates using non-stabilized $\mathrm{sp}^{2}$ - and $\mathrm{sp}^{3}$-hybridized nucleophiles. These reactions bear considerable resemblance to traditional $\mathrm{sp}^{2}-\mathrm{sp}^{2}$ cross-coupling reactions in terms of the starting materials used and the products obtained, but the reaction mechanisms are necessarily different.
\end{abstract}

\section{Introduction}

Transition-metal catalyzed cross-coupling reactions are some of the most important methods ever developed, with SuzukiMiyaura coupling arguably the most strategically important transformation used in industry. ${ }^{1}$ The discovery and development of these transformations resulted in the 2010 Nobel prize being awarded to Suzuki, Heck and Negishi (Scheme 1a).2,3 Transition metal complexes reliably form $\mathrm{Csp}^{2}$ $\mathrm{Csp}^{2}$ bonds by coupling aryl and alkenyl (pseudo)halides $(\mathrm{X}=$ $\mathrm{Cl}, \mathrm{Br}, \mathrm{I}, \mathrm{OTf}$, etc.) with unsaturated organometallic species $(\mathrm{M}=\mathrm{B}, \mathrm{Si}, \mathrm{Zn}, \mathrm{Zr}, \mathrm{Sn})$ and have been extensively developed to be highly tolerant of functional groups.

Efforts to develop asymmetric $\mathrm{Csp}^{2}-\mathrm{Csp}^{3}$ or $\mathrm{Csp}^{3}-\mathrm{Csp}^{3}$ crosscouplings have not yet yielded general solutions useful for complex molecule synthesis (Scheme 1b)..$^{1,4}$ The preparation of enantiomerically pure molecules still often relies on chiral pool strategies, but asymmetric reactions to prochiral substrates have also been widely developed. ${ }^{5}$ Methods involving racemic starting materials which undergo dynamic processes to give single enantiomer products are highly desirable as racemic substrates are far more abundant than meso or prochiral compounds. ${ }^{6,7}$

This Feature Article discusses recent advances in asymmetric $\mathrm{C}-\mathrm{C}$ bond formation using metal catalyzed dynamic asymmetric transformations which convert racemic starting materials into a highly enantioenriched products. While the focus is on methods developed in our laboratory we discuss related approaches for context, and in particular highlight work done by other groups that we have found inspirational.

Chemistry Research Laboratory, University of Oxford, 12 Mansfield Road, Oxford, OX13TA, UK. E-mail: stephen.fletcher@chem.ox.ac.uk

† Footnotes relating to the title and/or authors should appear here.

Electronic Supplementary Information (ESI) available: [details of any supplementary information available should be included here]. See DOI: $10.1039 / x 0 x \times 00000 x$

\section{C-C Cross-Coupling Reactions}

a) $\mathrm{Csp}^{2}-\mathrm{Csp}^{2}$ coupling, well developed, Nobel prize (2010)<smiles>[X]c1cc[R](C)cc1</smiles>

b) Asymmetric Csp ${ }^{2}-\mathrm{Csp}^{3}$ coupling, less developed

$$
R^{-M}+{ }_{R^{\prime}}^{X_{2}^{\prime}} \longrightarrow
$$

c) Our approach

$$
\underset{\substack{\text { racemic } \\ \text { non-stabilized }}}{\text { starting material }}
$$
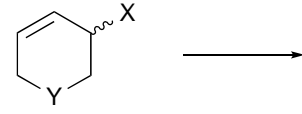

\section{Use of prochiral electrophiles}

Prior to catalytic asymmetric methods, chiral auxiliaries and stoichiometric reagents were often used to control absolute stereochemistry. ${ }^{8}$ The development of asymmetric 1,2(Scheme 2a) and 1,4-additions (Scheme 2b) to prochiral substrates represented major achievements for the field. ${ }^{8}$ Another powerful method to form $\mathrm{C}-\mathrm{C}$ bonds (Scheme $2 \mathrm{C}$ ) is asymmetric allylic alkylation (AAA). ${ }^{9-13}$ AAAs to prochiral allylic substrates are important processes as addition to the internal carbon atom provided chiral products featuring an alkene for further elaboration, but regio- as well as stereoselectivity is often difficult to control. 
a) Asymmetric 1,2-addition<smiles>[R]C([R])=O</smiles>

b) Asymmetric conjugate addition

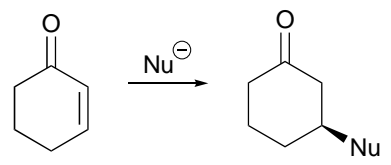

c) Asymmetric allylic alkylation

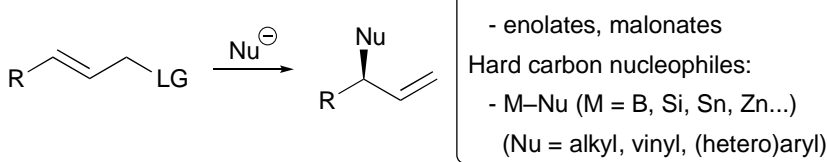

Scheme 2 Asymmetric additions to prochiral substrates.

\section{Asymmetric Cross-coupling}

Since Suzuki and Miyaura reported the cross-coupling of Csp²hybridised boronic acids with aryl halides in 1979,14 several strategies to achieve stereospecific Suzuki-Miyaura transformations have emerged. ${ }^{15}$ Starting from either single enantiomer alkylboronic acids ${ }^{16-20}$ or alkyl halides ${ }^{21-23}$ enantioenriched cross-coupling products can be formed with high enantiomeric excess via processes exhibiting either stereo-retention or -inversion at the initial stereogenic centre. In 2000, the synthesis of axially chiral biaryls via Pd-catalyzed coupling of boronic acids and aryl halides was reported independently by the Cammidge (Scheme 3a) ${ }^{24}$ and Buchwald groups, ${ }^{25}$ and many efforts have built upon this work to access atropisomeric products. ${ }^{26,27}$

Another asymmetric Suzuki-Miyaura strategy involves desymmetrization of meso compounds. ${ }^{28}$ Willis reported asymmetric Pd-catalyzed reactions with bis-vinyltriflates featuring a prochiral quarternary centre (Scheme $3 b) .29,30$ Lautens has developed Rh-catalyzed asymmetric arylation of cyclopenten-1,4-diol derivatives (Scheme 3c), $, 11,32$ as well as related desymmetrizations which ring-open oxabicyclic alkenes. ${ }^{33,34}$

More recently $\mathrm{Fu}$ and co-workers have reported a series of $\mathrm{Ni}$ catalyzed alkylations and arylations of racemic alkyl halides using boranes (Scheme $3 \mathrm{~d}$ ), ${ }^{35-37}$ as well as asymmetric decarboxylative $\mathrm{Csp}^{3}-\mathrm{Csp}^{2}$ cross-coupling by merging photoredox and nickel catalysis. ${ }^{38}$

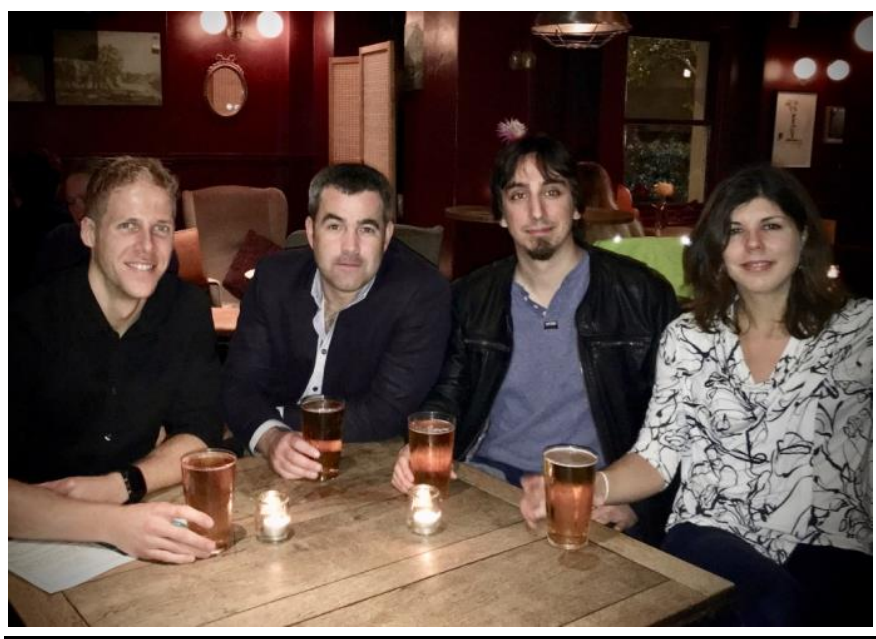

From left to right: Philipp Schäfer, Stephen P. Fletcher, Thomas Palacin, Mireia Sidera.

Philipp received his MSc from the Universität Paderborn in 2013, conducting research under the supervision of Prof. Christian Ducho. He is currently pursuing his PhD at the University of Oxford under the guidance of Prof. Stephen Fletcher, where he is investigating the reactivity of boronate and organosilicon complexes.

Steve was born in Halifax, Nova Scotia, Canada. He received a B.Sc. from Mount Allison University, and a PhD working with D. L. J. Clive (University of Alberta). He was an NSERC postdoctoral fellow in Ben Feringa's group in Groningen, and in 2007 joined Jonathan Clayden's group in Manchester. He started at the University of Oxford in 2009 as an EPSRC Career Acceleration Fellow and is currently Associate Professor and Fellow and Tutor in Chemistry at Keble College. His research interests include asymmetric catalysis, the origin of life, and dynamic stereochemistry.

Thomas received his Master degree from the University of Montpellier in 2013 as well as an engineer diploma from ENSCM (Ecole Nationale Supérieure de Chimie de Montpellier). He is currently pursuing his PhD at the University of Oxford under the supervision of Prof. Stephen P. Fletcher, where he is investigating the rapid access to the Taxol core and the enantioselective synthesis of tetrahydropyridines derivates.

Mireia Sidera was born in Barcelona, Catalonia. She received her undergraduate degree from the University of Barcelona. In 2011 she got her PhD in the same university working with Prof. Jaume Vilarrasa. In 2012 she joined Prof. Stephen Fletcher at the University of Oxford as a postdoctoral research associate. Her research interests include asymmetric catalysis and the synthesis of biologically active molecules. 


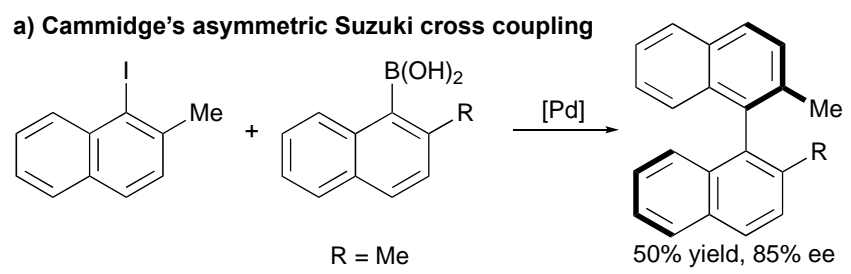

b) Willis' desymmetrisation of cyclopentadienes

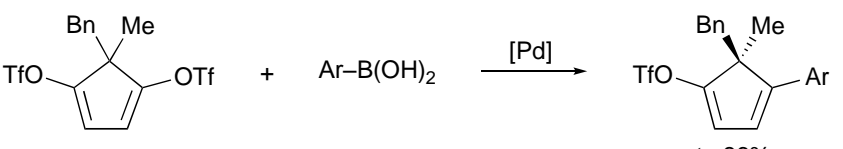
up to $86 \%$ ee

c) Lautens' desymmetrisation of cyclic diols<smiles>[R]O[C@H]1C=C[C@@H](O)C1</smiles>

$\mathrm{R}=\mathrm{CO}_{2} \mathrm{Et}$
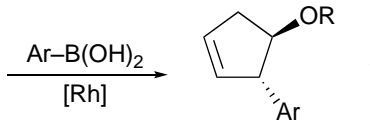

up to $92 \%$ ee

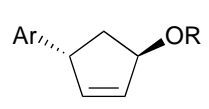

up to $99 \%$ ee d) Fu's $\alpha$-arylation of racemic $\alpha$-chloroamides

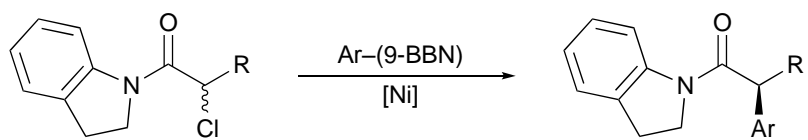

up to $88 \%$ yield, up to $94 \%$ ee

Scheme 3 Asymmetric Suzuki-Miyaura coupling reactions.

\section{Resolution, Kinetic Resolutions and Related Dynamic Processes}

A classical way to obtain single enantiomeric products, still widely used today, is resolution of racemic mixtures. In a kinetic resolution one enantiomer of the starting material is transformed to product faster than the other, thus providing access to enantioenriched products, but with a maximum yield of $50 \%$ (Scheme $4 a$ ). ${ }^{39}$ This is a vast area of chemical research and comprehensive authoritative books 40 can be complimented by contemporary reviews ${ }^{41-43}$ from a variety of perspectives.

Many efforts have been directed towards developing processes with over $50 \%$ yield in which both enantiomers are being transformed into a single stereoisomer. ${ }^{44,45}$ Direct enantioconvergent transformations (DET) where both starting material enantiomers follow separate mechanistic pathways to yield the same enantiomer of product are fairly rare and presumably difficult to design (Scheme 4b). 6,46,47

A more generally useful approach is to develop dynamic processes, where the starting material racemizes either during the reaction, or is recovered after the reaction, racemized and resubmitted to the reaction conditions, thus overcoming the $50 \%$ maximum yield problem. In a dynamic kinetic resolution (DKR) both enantiomers of the substrate interconvert in situ and $k_{\mathrm{rac}} \gg k_{\mathrm{R}} \gg k_{\mathrm{S}}$ allowing one enantiomer to react faster than the other and a single product to be obtained (Scheme 4c). 6,46,48

A related scenario is the dynamic kinetic asymmetric transformation (DYKAT) where there is no resolution, but both enantiomers of the starting material are converted into a single enantiomer product. DYKATs have been previously classified according to their mechanism. In a type I DYKAT the substrate reacts with a chiral catalyst to form a mixture of diastereomeric intermediates, one of which is favoured to give the product (Scheme 4d). ${ }^{49,50,51}$ In a type II DYKAT the catalyst desymmetrizes the substrate to form an enantiomeric intermediate that preferentially affords one product (Scheme 4e).

De-epimerisation reactions ${ }^{6,46}$ and other de-racemisation reactions, e.g. stereoablative transformations ${ }^{52,53}$ are also known.

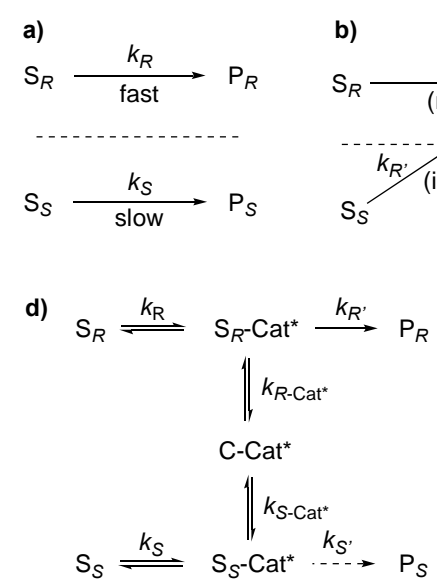

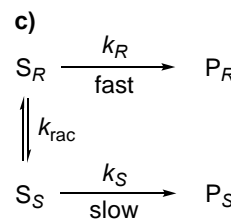

e)

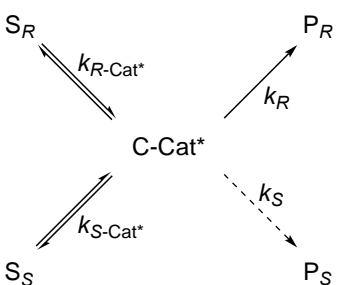

Scheme 4 a) Kinetic resolution; b) Direct enantioconvergent transformation; c) DKR with racemising starting material; d) DYKAT with interconverting intermediates; e) DYKAT occurring via formation of a common intermediate.

\section{Asymmetric Allylic Alkylation (AAA)}

Highly enantioselective AAA methods with racemic starting materials have been extensively developed using palladium catalysts and stabilized nucleophiles.9,13,54-56 It is generally understood that both enantiomers of the substrate react with the palladium catalyst to form a common pseudo-prochiral ? $\pi$ allyl intermediate and the product is formed during stereoselective attack of the nucleophile. ${ }^{57,58}$

A wide variety of stabilized nucleophiles have been employed in these processes. ${ }^{59}$ Stabilized or soft nucleophiles are generally defined as having a $\mathrm{p} K_{\mathrm{a}}$ of $<25$, and include carbonyl derivatives (for example malonates, Scheme $5 a$ ) as well as many heteroatom nucleophiles. With these nucleophiles the key bond-breaking and -forming events normally occur outside the coordination sphere of the metal (Fig. 1, left), and enantioselectivity is obtained by controlled attack of the nucleophile at allylic carbons of the $\pi$-metal complex.

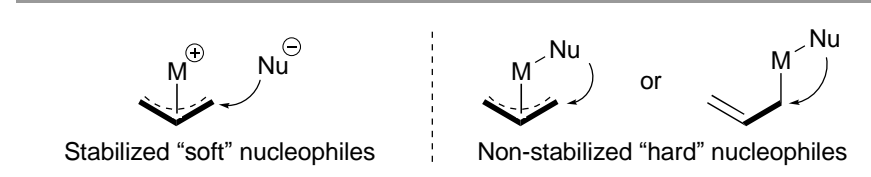

Figure 1 Mechanistic pathways of stabilized and non-stabilized nucleophiles. 
As well as using racemic electrophiles, racemic nucleophiles can undergo resolutions, for example with $\beta$-ketoesters where the catalyst differentiates between two faces of the prochiral enolate (Scheme 5b). ${ }^{60}$ As well as $\mathrm{Pd}$, other transition metals such as molybdenum ${ }^{61,62}$ and iridium ${ }^{63-65}$ have seen extensive use in AAAs (Scheme $5 c, d$ ).

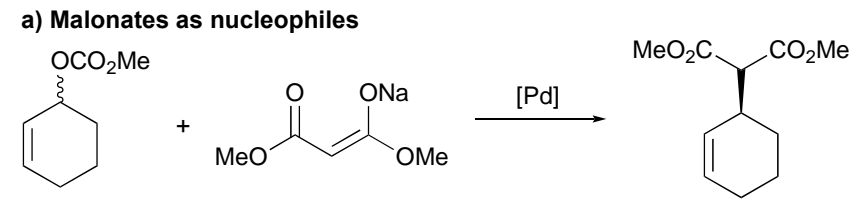

$86 \%$ yield, $96 \%$ ee

b) -Keto-ester as prochiral nucleophiles

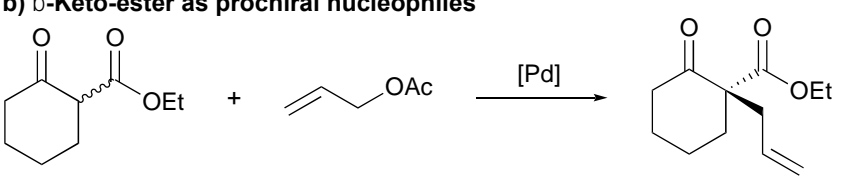

c) Molybdenum catalyzed AAA<smiles>C=CC[C@]1(C)C(=O)Nc2ccc(OC)cc21</smiles>

$98 \%$ yield, $82 \%$ ee

d) Iridium catalyzed AAA

$$
\underbrace{\mathrm{OBz}}_{\mathrm{OMe}} \stackrel{[\mathrm{Ir}]}{\longrightarrow}
$$

Scheme 5 Asymmetric allylic alkylations using soft nucleophiles

\section{AAA with Non-stabilized Nucleophiles}

Non-stabilized nucleophiles $\left(p \mathrm{~K}_{\mathrm{a}}>25\right)$, a huge category of structures which includes most alkyl, benzylic and (hetero)aromatic groups, undergo Pd-catalyzed Tsuji-Trost type allylic chemistry using different mechanistic pathways. These more reactive coupling partners generally attack at the metal centre (Fig. 1, right), and then the product is formed by a reductive elimination type process.

While AAA procedures with stabilized nucleophiles and racemic substrates are well established, the use of nonstabilized nucleophiles in these enantioselective reactions is far less developed but not unknown. For example, Trost and co-workers developed highly enantioselective Pd-catalyzed procedures using less-stabilized nucleophiles such as benzylic pyridines $^{66,67}$ and other nitrogen rich heterocycles ${ }^{68}$ (Scheme 6).
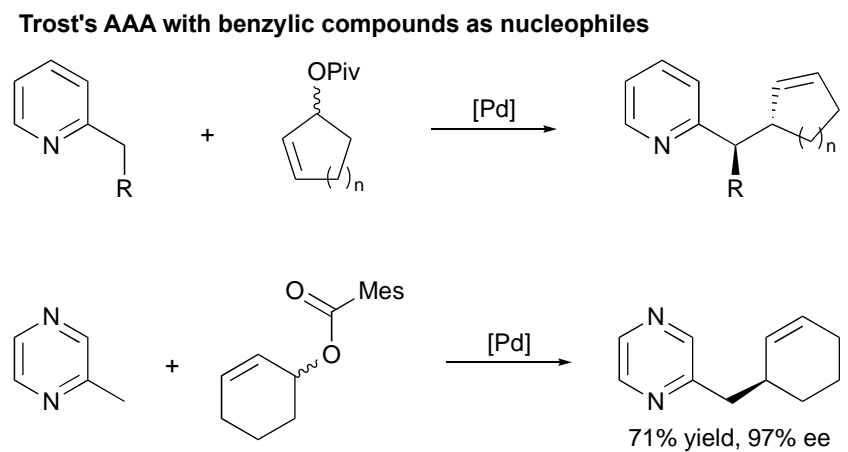

Scheme 6 Pd-catalyzed AAA of benzylic nitrogen-rich heterocycles.

\section{Cu-catalysed AAAs with Grignard reagents}

The use of alkyl nucleophiles in asymmetric catalysis often relies on Cu-catalysis. ${ }^{69,70}$ It is generally accepted that $\mathrm{Cu}$ catalyzed AAAs occur via regiospecific anti-addition where an $\mathrm{S}_{\mathrm{N}} 2$ ' oxidative addition is the rate-determining step. In contrast with Pd-catalysis, Cu-allyl intermediates lack an efficient $\sigma$ - to $\pi$-isomerization, so if the reductive elimination is fast, racemic starting materials are expected to lead to racemic products. ${ }^{71}$ Alexakis and co-workers used Grignard reagents in a coppercatalyzed AAA with a racemic allyl bromide (Scheme 7)..$^{72}$ However, the authors found the reaction scope to be limited, and further investigations showed that the reaction involved a direct enantioconvergent process whereby each enantiomer of the starting material followed a different mechanistic pathway to the same enantiomer of the product. ${ }^{73}$

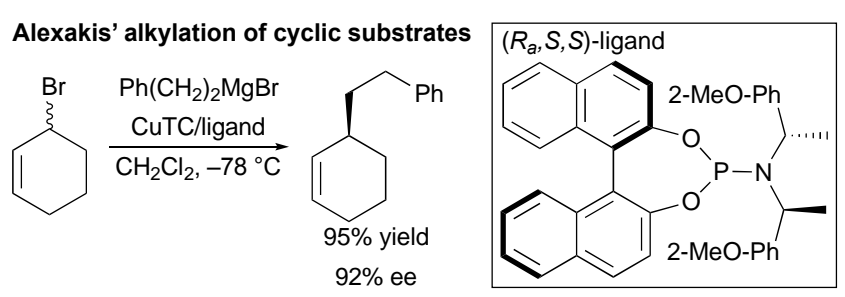

Scheme 7 Cu-catalyzed AAA of Grignard reagents.

\section{Cu-catalyzed AAA with alkylzirconium reagents}

We have developed highly enantioselective conjugate addition reactions of alkylzirconium reagents..$^{74-77}$ In 2015, we reported that alkylzirconium species can also be used in AAAs to racemic cyclic allylic halides ${ }^{78}$ using the combination of $\mathrm{Cul}$ and phosphoramidite ligand $\mathbf{A}^{79}$ (Fig. 2).

The scope of the nucleophile ranges from gaseous, shortchained alkenes to more complex alkenes bearing stereogenic centers. A variety of functional groups are tolerated including protected alcohols, silanes and halides, and the method can easily be scaled to grams of product (Scheme 8a). Good results were obtained with five-membered ring allyl chlorides, which is noteworthy because 5-membered electrophiles often behave poorly in $\mathrm{Cu}$-catalyzed conjugate additions. Alkylation products can be converted to more complex structures (Scheme $8 \mathrm{~b}$ ) and were used to make cyclopentene-containing antituberculosis and antileprosy agents hydnocarpic acid, chaulmoogric acid and anthelminthicin C (Scheme 8c). In a 
follow-up study we investigated the use of oxygen containing electrophiles. 3,6-Dihydro-2H-pyranyl chloride undergoes asymmetric alkylation albeit with low yields despite extensive screening. ${ }^{80}$

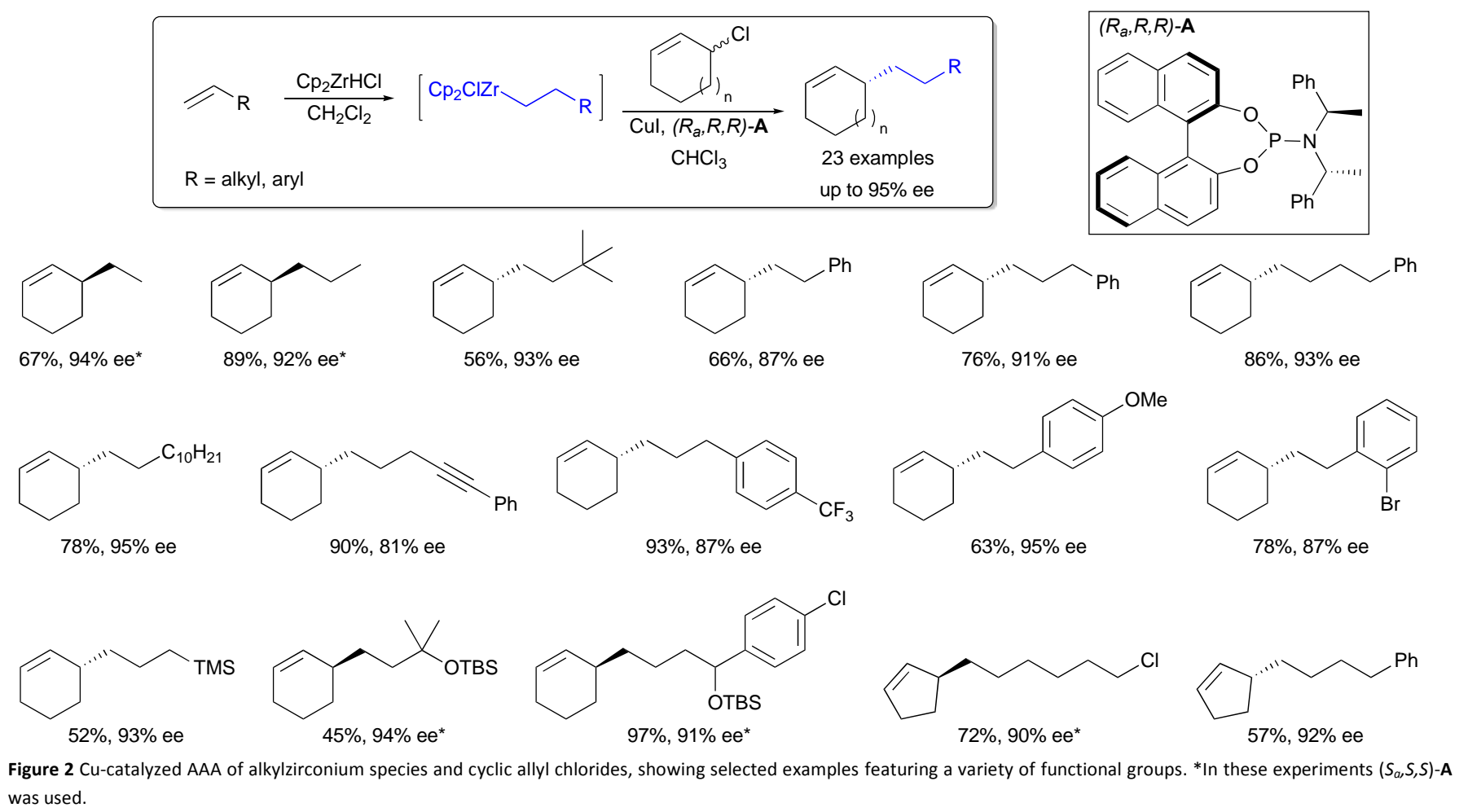
was used.

\section{a) Selected scale-up reaction}

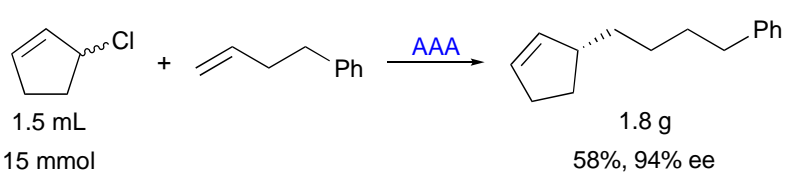

b) Intramolecular Heck-reaction

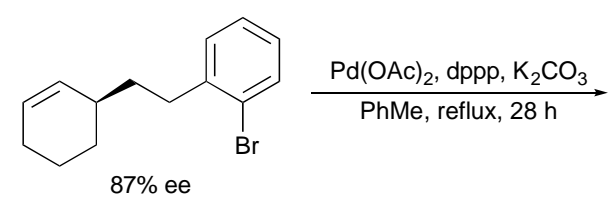

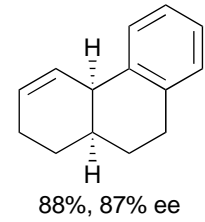

$88 \%, 87 \%$ ee

c) Applications for the synthesis of natural products

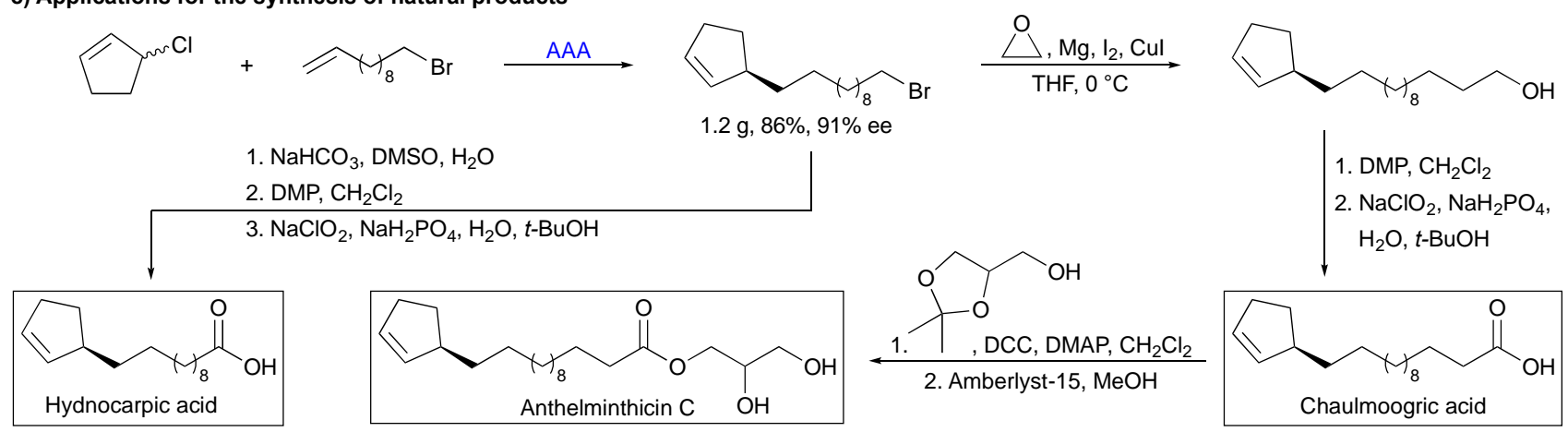

Scheme 8 a) Scale-up reaction; b) Intramolecular Heck reaction; c) Use of the AAA as key step for the synthesis of cyclopentene containing natural products.

In the case of starting materials with certain substitution patterns it is possible to resolve mixtures of racemic diastereoisomers (Scheme 9). For example, addition of 1hexene to a mixture of racemic cis- and trans-5-phenyl allyl chloride $(4: 1)$ resulted in a single enantioenriched product with the cis configuration ( $66 \%$ yield, $93 \%$ ee). 
<smiles>ClC1C=CC[C@H](c2ccccc2)C1</smiles>

(士)-trans<smiles>C[C@@H]1C=CC[C@H](c2ccccc2)C1</smiles>

$( \pm)$-cis

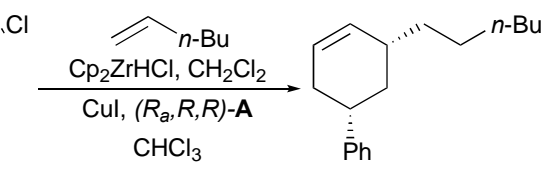

$(R, R)$-cis
Scheme 9 Cu-catalyzed conversion of a mixture of two racemic allyl chlorides to a single enantioenriched product.

\section{Mechanistic studies}

In order to understand how the reaction works we performed extensive NMR studies. Kinetics obtained by ${ }^{1} \mathrm{H}-\mathrm{NMR}$ spectroscopy showed clean conversion of the allyl chloride to product along with the constant presence of an allyl iodide in small ( 3\%) amounts. NMR EXSY experiments suggest that this allyl halide interconverts or racemizes on the NMR timescale (Fig. 3), and further experiments using allyl bromide starting materials demonstrated that allyl halide interconversion is mediated by the Cul-A complex and occurs via $\mathrm{S}_{\mathrm{N}} 2^{\prime}$ pathways. Later, we were able to quantify the rate of allyl iodide interconversion as $0.10 \pm 0.01 \mathrm{~s}^{-1}$, using three related NMR spectroscopy methods. It is assumed that the allyl iodide formation is a key part of a mechanism for allyl chloride racemization (Fig. 3b). When $\mathrm{CuCl}$ or $\mathrm{CuBr}$ are used instead of $\mathrm{Cul}$, the reaction works but is less enantioselective $(49 \%$ and $73 \%$ respectively) - presumably halides that are better nucleophiles and leaving groups facilitate the rate of halide interconversion / racemization. ${ }^{81}$

Evidence that AAA occurs via the catalyst selecting one enantiomer of a rapidly isomerizing mixture was obtained by following the ee of these reactions in time using different copper sources. When $\mathrm{CuCl}$ is used the reaction is faster but the ee decreases in time (from $82 \%$ at $10 \mathrm{~min}$ to $54 \%$ ee at completion). EXSY experiments did not show isomerisation of the allyl chloride with the $\mathrm{CuCl}$-based catalyst on the NMR timescale and it is likely that as the reaction progresses the least preferred enantiomer of the substrate starts reacting. Supporting this, SM recovered during the reaction becomes enantioenriched ( $7 \%$ ee after $1 \mathrm{~h},>11 \%$ ee after $2 \mathrm{~h}$ ).

Most surprisingly, when using Cul, the ee of the reaction was found to increase over time (from $85 \%$ ee at $10 \mathrm{~min}$ to $95 \%$ ee at completion). In situ ${ }^{1} \mathrm{H}-\mathrm{NMR}$ spectroscopy was used to collect kinetic data which was fitted to a model, and this data along with EXSY and DOSY experiments suggested that the catalyst evolves in time to become more efficient and more enantioselective. The initial catalyst is believed to be dimeric, i.e. $\mathrm{Cu}_{2} \mathrm{I}_{2} \mathrm{~A}_{2}$, but as the reaction progresses and $\mathrm{Cl}^{-}$is released from the substrate a more selective catalytic complex containing both $\mathrm{I}$ and $\mathrm{Cl}$ anions, such as $\mathrm{Cu}_{2} \mid \mathrm{ICl}_{2}$, is produced which is 3 times faster than the original catalyst.

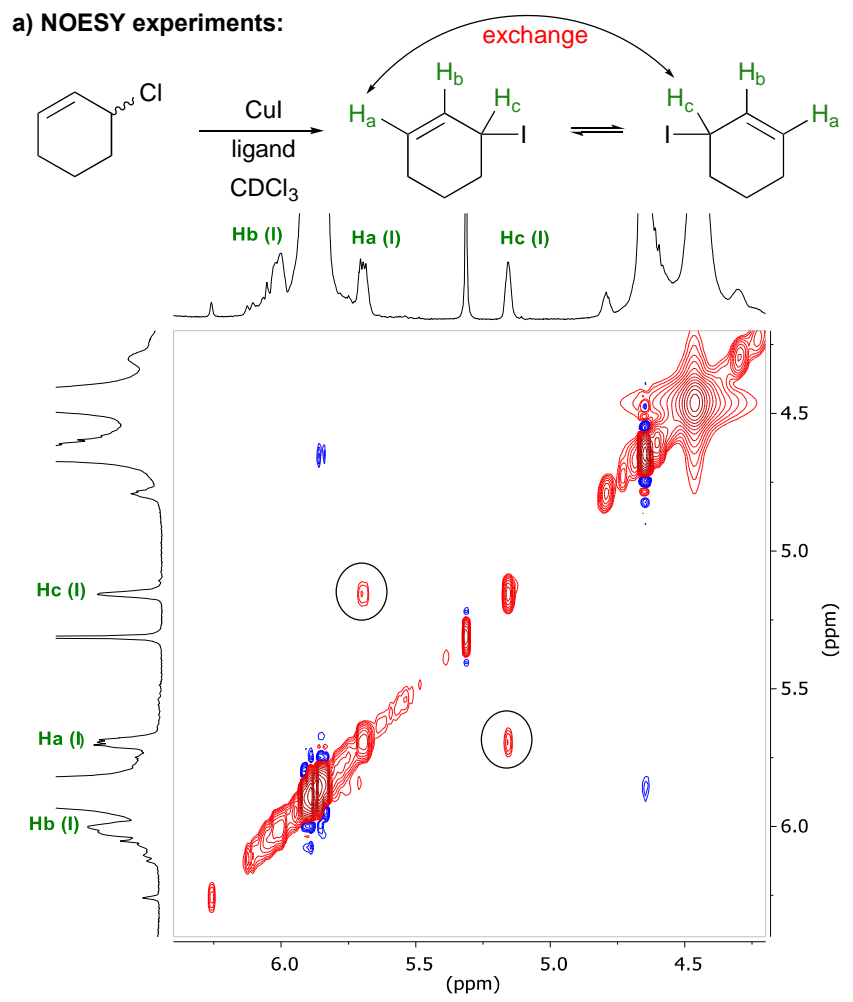

b) Racemization of racemic allyl chloride via an iodide substitution<smiles>IC1C=CCCC1</smiles><smiles></smiles><smiles>Cl[C]1C=CCCC1</smiles>

Cul-A

fast<smiles>IC1C=CCCC1</smiles>

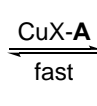

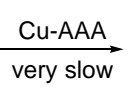
very slow major product $(>90 \%$ ee $)$
Figure 3 a) (NOESY) EXSY spectrum shows the exchanging protons of the allyl iodide; b) Proposed mechanism: racemization of starting material via an allyl iodide intermediate and selective reaction of one enantiomer of starting material. Reprinted with permission from ref. 81. Copyright (2017) American Chemical Society.

\section{Cu-catalyzed AAA of allylic phosphates}

We then aimed to use less reactive electrophiles in this process, which would be less prone to isomerization during preparation and manipulation, and may aid in mechanistic studies. Allylic phosphates gave promising results, and after optimisation the best results were obtained using Cul, ligand B and addition of $\mathrm{TMSCl}$ as an additive (Scheme 10a). In the absence of TMSCl the yields and ee's were both lower and the results were variable from run to run. It should be noted that the allyl chloride system is superior to the phosphates in terms of robustness and generality. Ligand B was found to be useful in all AAAs examined, generally providing higher levels of ee, and is necessary to get effective reactions with sevenmembered rings (Scheme 10b). 
a) Cu-catalyzed AAA with allylic phosphates

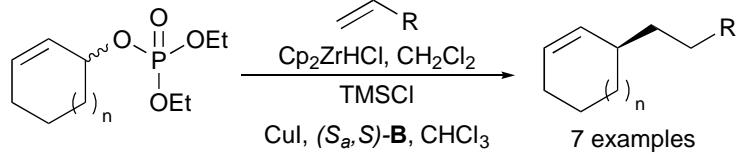

$$
\begin{aligned}
& \text { up to } 93 \% \text { ee }
\end{aligned}
$$

b) Cu-catalyzed AAA with cycloheptenyl chloride<smiles>Cl[C@H]1C=CCCCC1</smiles>

$$
\underset{\mathrm{Cul},\left(\mathrm{S}_{a}, \mathrm{~S}\right)-\mathrm{B}, \mathrm{CHCl}_{3}}{\stackrel{\mathrm{Cp}}{\mathrm{ZrHCl}, \mathrm{CH}_{2} \mathrm{Cl}_{2}}}
$$

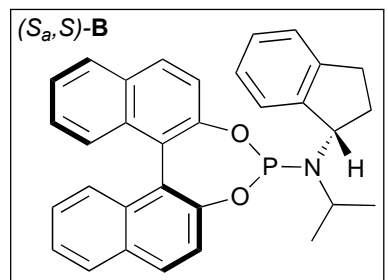

Scheme 10 a) Cu-catalyzed AAAs using allylic phosphates and ligand B; b) Cu-catalyzed AAAs to seven-membered rings.

In situ ${ }^{1} \mathrm{H}$ NMR spectroscopy using the allyl phosphate and the optimised conditions with $\mathrm{TMSCl}$ (Fig. 4a) shows that the starting material is rapidly and entirely consumed to give an allyl chloride intermediate. Presumably the allyl chloride is produced from reaction of the starting material with $\mathrm{TMSCl}$. In this system, an allyl iodide is seen to form very fast and reach a maximum concentration of $\sim 10 \%$ in 2 min and then appears to be consumed within $30 \mathrm{~min}$. Although signals characteristic of allyl halide isomerization were never observed by in situ EXSY experiments during AAAs with allyl phosphates, it seems likely that once the allyl chloride is formed here it also undergoes racemization via the allyl iodide. Kinetic modelling indicated that the allyl chloride reacts $20 \times$ faster than the phosphate and formation of the allyl chloride is $5 \mathrm{x}$ faster than AAA.

Unexpectedly, when no TMSCl is used with the allyl phosphate (Fig. 4b) the reaction still goes via an allyl chloride intermediate. In the absence of $\mathrm{TMSCl}$, the allyl chloride is likely initially generated from adventitious $\mathrm{Cl}^{-}$from reaction components $\left(\mathrm{Cp}_{2} \mathrm{ZrClEt}\right.$ or $\left.\mathrm{CH}_{2} \mathrm{Cl}_{2}\right)$. As the reaction progresses $\mathrm{Cl}^{-}$is also released from the substrate. Given how commonly allyl phosphates are used as electrophiles in chemistry, and the apparent ease of which the allyl chloride forms, it seems likely that in situ allyl chloride formation is involved in the mechanism of other chemical reactions.

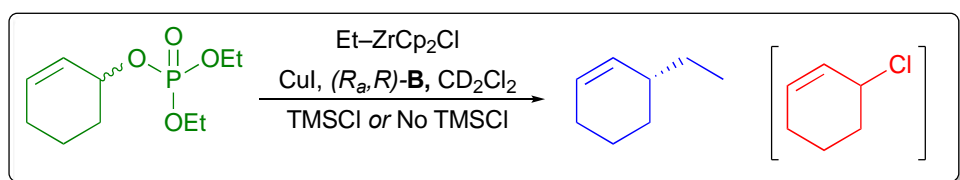

a)

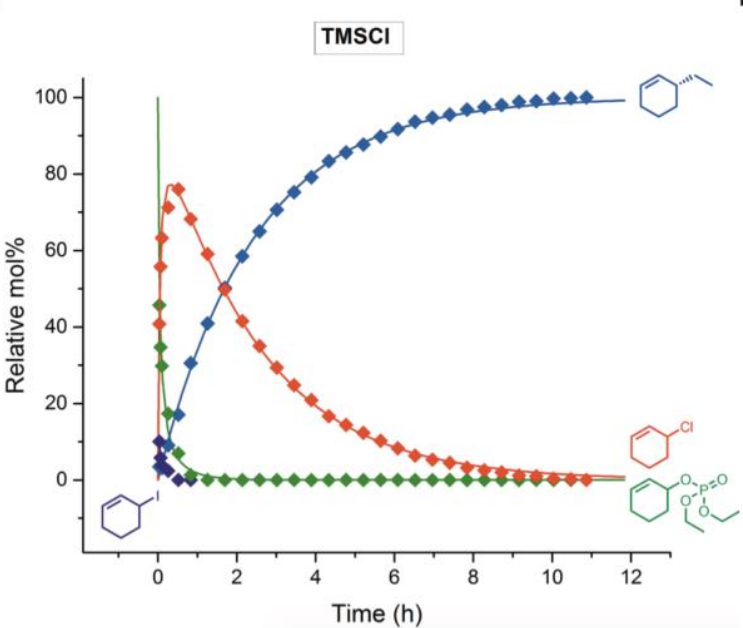

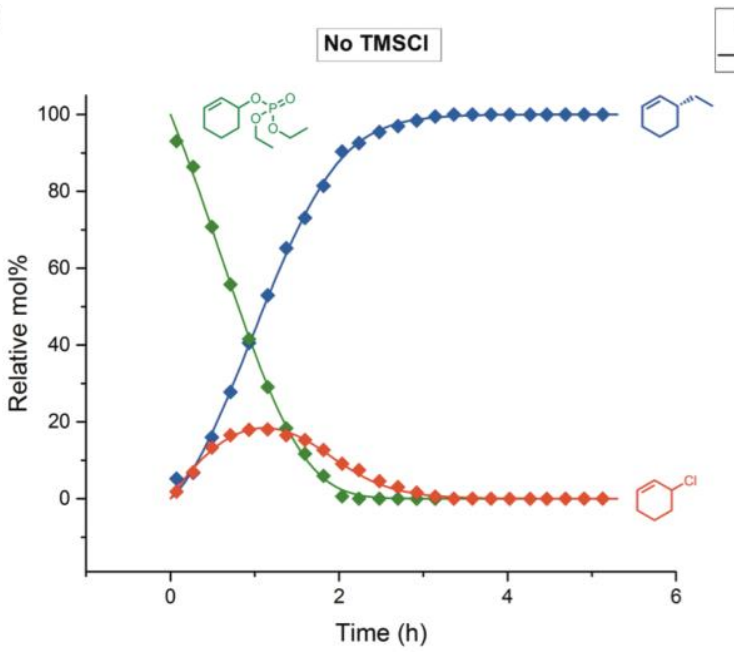

Experimental data Fitted model

Figure $4{ }^{1} \mathrm{H}$-NMR spectra of the Cu-catalyzed AAA of racemic allyl phosphates with (a) and without (b) TMSCl. Reprinted with permission from ref. 81. Copyright (2017) American Chemical Society.

\section{Cu-catalyzed asymmetric allylic alkenylation}

The successful development of a system capable of adding alkyl nucleophiles encouraged us to explore DYKAT processes with $\mathrm{sp}^{2}$-hybridised nucleophiles (Scheme 11a). ${ }^{82}$ We explored alkenyl-zirconocenes and found reaction optimisation nontrivial. After extensive exploration CuOTs (prepared in situ from $\mathrm{CuCl}$ and $\mathrm{AgOTs}$ ) in combination with allyl bromides gave the best results, although the enantioselectivity was low. In order to assist with determining the stereoselectivity with which the dienes formed, enantiomerically pure alkynes featuring a TBS-protected alcohol were used so that the diastereomeric ratio could be determined by NMR 
spectroscopy (Scheme 11b). Coupling to a 7-membered cyclic allyl bromide gave product in $56 \%$ yield with a diastereomeric ratio of 81:19 d.r. (Scheme 11c).

a) Alkenylation of cyclic allyl bromides<smiles></smiles>

b) Use of chiral alkynes<smiles>C#CCC(C)[OH2+]</smiles>

$>99: 1$ ee

or<smiles>C#CCC(C)[OH2+]</smiles>

$>99: 1$ ee
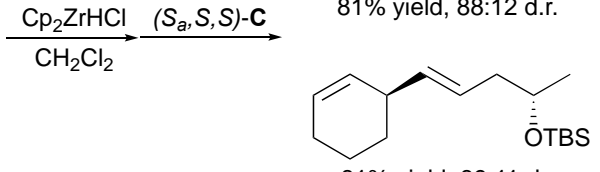

$81 \%$ yield, $89: 11$ d.r. c) Cu-catalyzed alkenylation with 7-membered ring
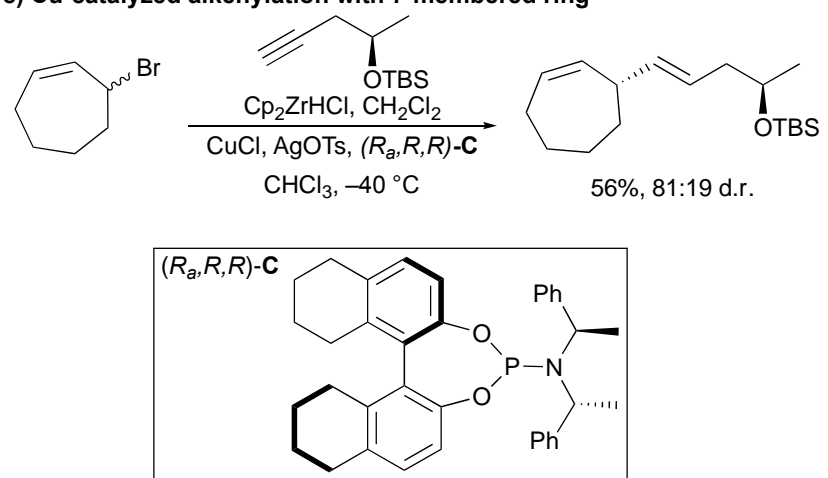

Scheme 11 Asymmetric alkenylation with racemic cyclic allyl bromides.

\section{Rh-catalyzed asymmetric allylic arylation}

Given the difficulty in developing an asymmetric addition using $\mathrm{sp}^{2}$-hybridised zirconium nucleophiles we considered the use of boronic acid nucleophiles. These have been extensively explored in enantioselective conjugate additions using $\mathrm{Rh}$ catalysts, $^{83}$ although the use of $\mathrm{Rh}$ in asymmetric allylic substitutions is far less known. ${ }^{31-34,84-86}$

Suzuki-Miyaura couplings to synthesize enantioenriched compounds are known but most procedures involve enantiopure starting materials ${ }^{15}$ or deracemization reactions, ${ }^{28,31}$ though there are notable exceptions. ${ }^{35,38}$ And it remains a long standing challenge to find methods to form $\mathrm{Csp}^{2}-\mathrm{Csp}^{3}$ bonds that can serve as synthetic tools in medicinal chemistry and drug-discovery. ${ }^{87-89}$

We tested numerous conditions for an enantioselective Suzuki-Miyaura reaction and after extensive optimisation found that arylboronic acids can be added to racemic cyclic allyl halides using $[\mathrm{Rh}(\mathrm{cod}) \mathrm{OH}]_{2}$ and (S)-Xyl-P-PHOS (Fig. 5)..$^{90}$ Generally, highly enantioenriched products are obtained in excellent yields with both electron-deficient and -rich arylboronic acids. Later experiments revealed that different ligands could be used with similar levels of enantioselectivity and that allyl bromides can also be used.
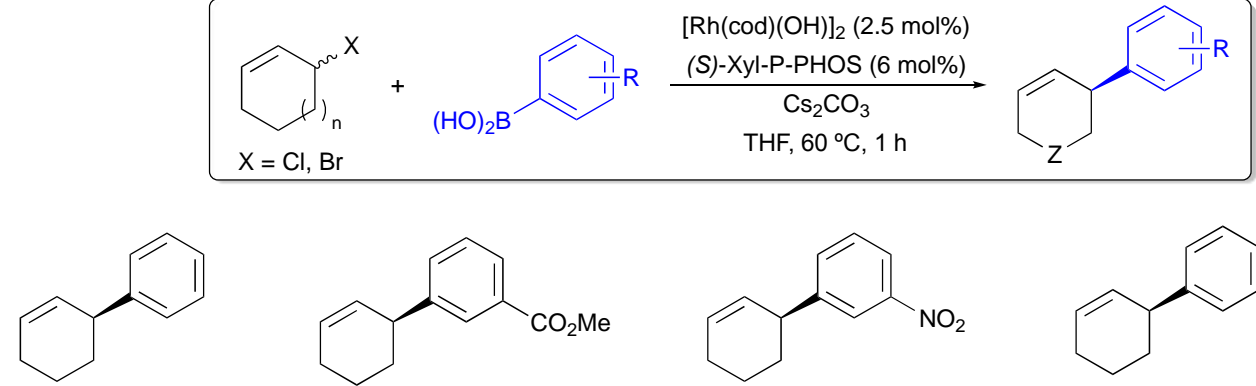

$99 \%, 99 \%$ ee<smiles>COc1ccc([C@H]2C=CCCC2)cc1</smiles>

$77 \%, 97 \%$ ee<smiles>COc1cccc(C2C=CCCC2)c1</smiles>

$86 \%,>99 \%$ ee<smiles>CS[Se-]c1ccc([C@H]2C=CCCC2)cc1</smiles>

$40 \%, 99 \%$ ee<smiles>O=[N+]([O-])c1cccc(C2C=CCCC2)c1</smiles>

$51 \%, 96 \%$ ee

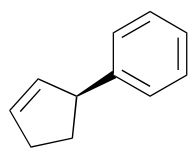

$67 \%,>99 \%$ ee<smiles>C1=CC(c2ccccc2)CCC1</smiles>

$62 \%, 97 \%$ ee<smiles>Brc1cccc(C2C=CCCC2)c1</smiles>

$56 \%, 96 \%$ ee<smiles>C1=CC(c2ccccc2)COC1</smiles>

$99 \%, 96 \%$ ee
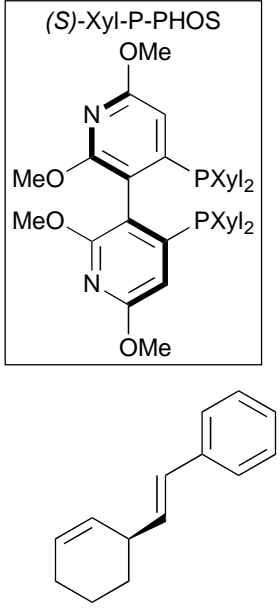

$67 \%, 96 \%$ ee

Figure 5 Selected examples for the Rh-catalyzed asymmetric allylic arylation of racemic allyl halides.

Different cis/trans mixtures of 5-phenyl substituted allyl chlorides were prepared and examined (Table 1). In contrast to 
the stereoselectivity observed in the $\mathrm{Cu}(\mathrm{I})$-catalyzed system, here a DYKAT mechanism occurs with overall inversion of configuration.

Table 1 Stereoselectivity of allylic arylation

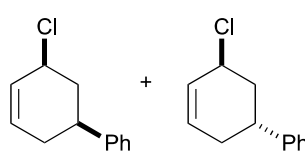

$( \pm)$-cis

$( \pm)$-trans

$$
\begin{gathered}
\mathrm{PhB}(\mathrm{OH})_{2} \\
{[\mathrm{Rh}(\mathrm{cod})(\mathrm{OH})]_{2}} \\
\stackrel{(\mathrm{S})-\mathrm{Xyl}-\mathrm{P}-\mathrm{PHOS}}{\underset{\mathrm{Cs}_{2} \mathrm{CO}_{3}}{\longrightarrow}} \\
\mathrm{THF}, 60{ }^{\circ} \mathrm{C}, 18 \mathrm{~h}
\end{gathered}
$$

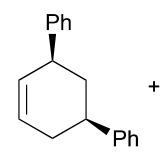

$(S, S)-c i s-P$

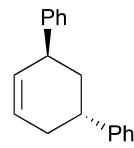

$(S, R)$-trans- $P$

\begin{tabular}{ccccccc}
\hline Entry & $\begin{array}{c}\text { SM cis: } \\
\text { trans }^{\mathbf{a}}\end{array}$ & $\begin{array}{c}\text { Conversion } \\
(\%)\end{array}$ & $\begin{array}{c}\text { Remaining SM } \\
\text { cis:trans }^{\mathbf{a}}\end{array}$ & $\begin{array}{c}\text { P cis: } \\
\text { trans }^{\mathbf{a}}\end{array}$ & $\begin{array}{c}\text { cis-P } \\
\mathbf{e e}^{\boldsymbol{b}}(\%)\end{array}$ & $\begin{array}{c}\text { trans- } \boldsymbol{P} \\
\mathbf{e e}^{\boldsymbol{b}}(\%)\end{array}$ \\
\hline 1 & $1: 25$ & 100 & - & $25: 1$ & $>99$ & 98 \\
2 & $1: 5.3$ & 100 & - & $5.3: 1$ & $>99$ & $>99$ \\
3 & $6.1: 1$ & 100 & - & $1: 5.3$ & 98 & $>99$ \\
$4^{c}$ & $6.1: 1$ & 84 & $>50: 1$ & $1: 4.5$ & 97 & $>99$ \\
\hline
\end{tabular}

Conditions: 3-chloro-5-phenylcyclohex-1-ene (1.0 eq), benzeneboronic acid (2.0 eq), $[\mathrm{Rh}(\mathrm{cod})(\mathrm{OH})]_{2}$ (2.5 mol\%), (S)-Xyl-P-PHOS (6 mol\%), $\mathrm{Cs}_{2} \mathrm{CO}_{3}(1.0 \mathrm{eq})$ in THF at $60{ }^{\circ} \mathrm{C}$ stirring for $18 \mathrm{~h}$.

${ }^{a}$ Determined by ${ }^{1} \mathrm{H}$-NMR spectroscopy. ${ }^{b}$ Determined by chiral HPLC. ${ }^{c}$ Reaction stopped after $3 \mathrm{~h}$.
When the ratio of substrate is 1:5.3 in favour of trans, the cis product is again major with complete inversion. When the cis starting material is in excess (6.1:1 ratio) the trans product is favoured although with a slightly altered (1:5.3) ratio. This latter reaction, when the reaction was stopped before completion (84\% conversion) gave a lower product ratio of $1: 4.5$, with recovered allyl chloride having a $>50: 1$ ratio in favour of cis. These observations suggest that the trans allyl chloride reacts faster, and we speculate that there is a partial cis-to-trans isomerization during the reaction.

These results encouraged us to explore more challenging coupling partners. ${ }^{91}$ In particular, despite their vital role in biologically active molecules, there is a lack of generally useful ways to prepare enantiopure heterocycles. ${ }^{4,92,93}$ The asymmetric Suzuki-Miyaura coupling proved extremely robust and we found that a number of bidentate phosphine ligands can be employed with comparable results. BINAP - and in some cases Xyl-P-PHOS - is generally the best ligand for the majority of transformations involving vinyl- and $\beta$ styrenylboronic acids

(Fig. 6).

When using a 1:25 cis/trans ratio of diastereomeric starting materials, the cis-product is the major product in a 25:1 ratio.

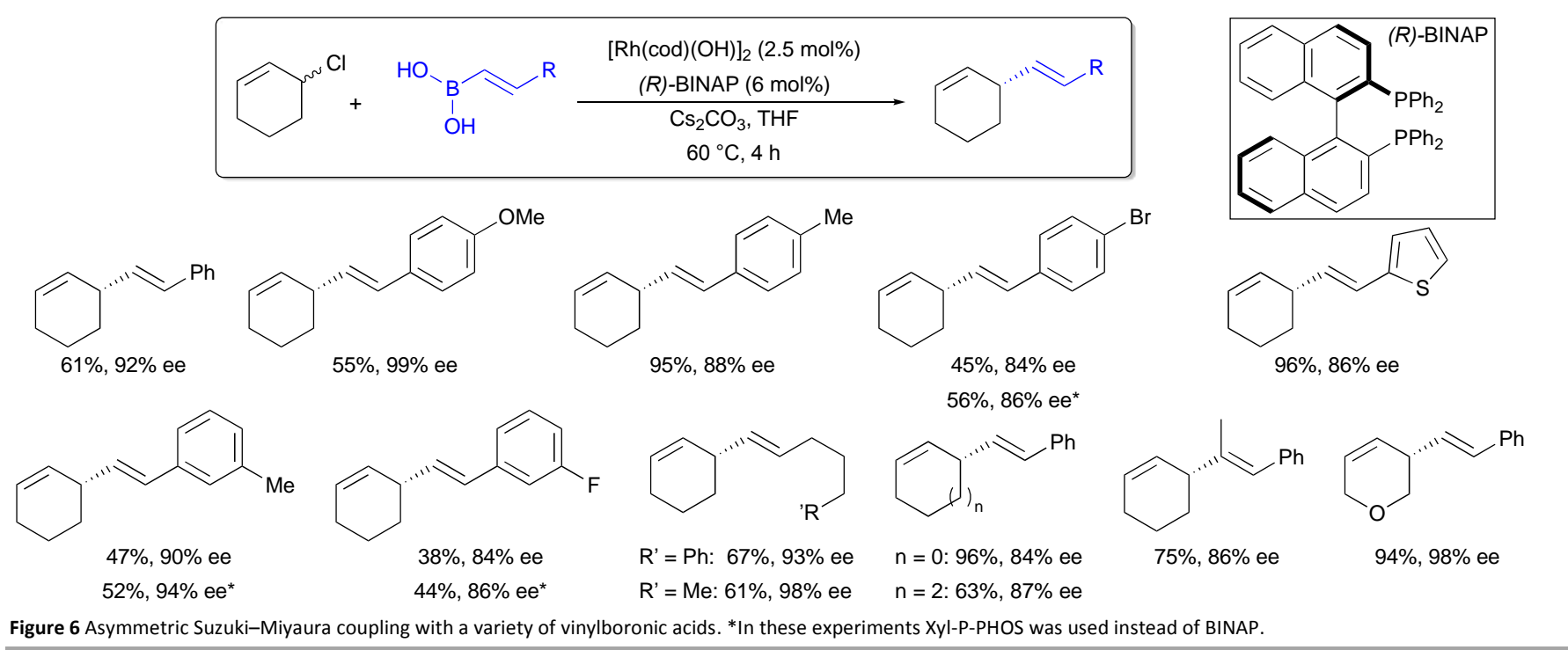



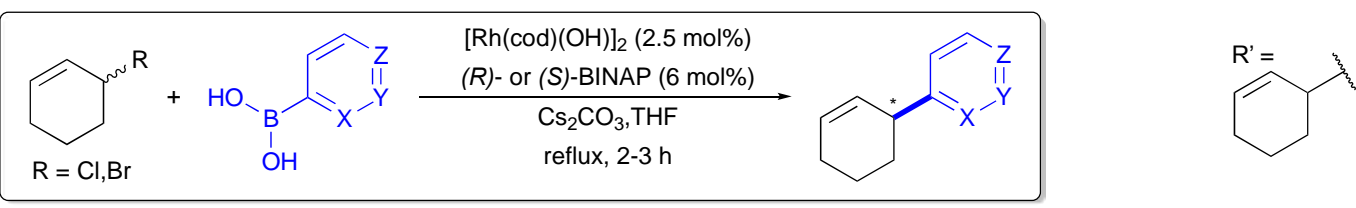

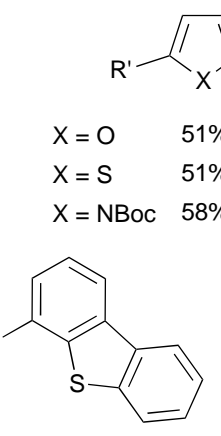

$57 \%, 90 \%$ ee

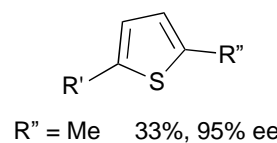

$\mathrm{R} "=\mathrm{CHO} 30 \%,>99 \%$ ee

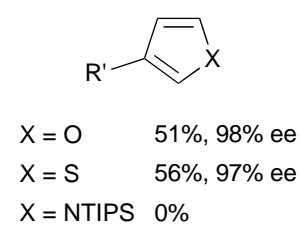

$$
\begin{array}{ll}
\mathrm{X}=\mathrm{O} & \begin{array}{l}
75 \%, 95 \% \mathrm{ee}^{*} \\
\mathrm{X}=\mathrm{S}
\end{array} \\
\mathrm{X}=\mathrm{NB} \text { oc } & 20 \%, 99 \% \text { ee* }
\end{array}
$$

Figure 7 Asymmetric Suzuki-Miyaura coupling with heteraromatic boronic acids. *In these experiments Xyl-P-PHOS was used instead of BINAP

\section{Rh-catalysed Addition of Pyridinylboronic Acids}<smiles>[R6]c1cccnc1</smiles>

no reaction<smiles>Clc1ncccc1[C]1C=CCCC1</smiles>

$26 \%, 97 \%$ ee

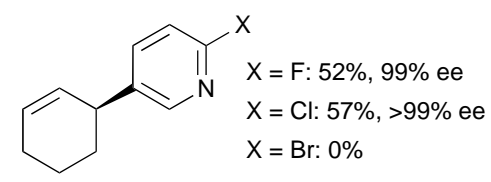<smiles></smiles>

$44 \%, 99 \%$ ee<smiles>Clc1cccc([C@H]2C=CCCCC2)n1</smiles><smiles>Clc1cccc(C2C=CCCC2)n1</smiles>

$63 \%, 97 \%$ ee<smiles>Clc1cccc([C@H]2C=CCOC2)n1</smiles>

$74 \%, 99 \%$ ee
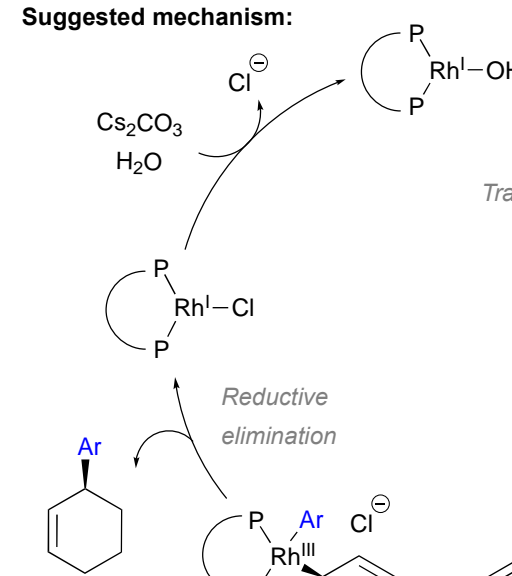

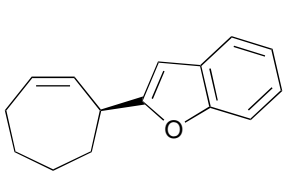

$34 \%, 98 \%$ ee

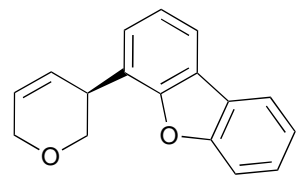

$60 \%, 98 \%$ ee<smiles>Cc1cccc(C2C=CCC2)n1</smiles>

$28 \%, 80 \%$ ee

$$
22 \%, 85 \% \text { ee }
$$

Figure 8 left: Products of the asymmetric Suzuki-Miyaura coupling with 2-halopyridines; right: Proposed mechanistic pathway of the asymmetric Suzuki-Miyaura coupling.

In Suzuki-Miyaura couplings some heteroarylboronic acids are well known to undergo rapid competitive protodeboronation. ${ }^{94}$ Here furans, thiophenes, benzofurans and benzothiophenes readily undergo asymmetric coupling with high yields and enantioselectivities (Fig. 7). $\mathrm{N}$-Heterocyclic nucleophiles such as $\mathrm{N}$-Boc protected pyrrole and 5- and 6indolylboronic acid also performed well, but other indolsubstitution patterns gave poor results, which appears to be due to the instability of the boronic acids under the reaction conditions.

\section{Coupling pyridine derivatives}

Arguably, one of the most valuable heterocycles is pyridine which plays a key role in catalysis, drug design, molecular recognition and is present in many natural products. ${ }^{92}$ Pyridylboronic acids are known to be challenging coupling partners. ${ }^{95}$ Initial attempts to use pyridylboronic acids and derivatives did not provide coupling products. However, 2halogenated pyridines work well under the reaction conditions
(Fig. 8, left). We believe that the presence of the electronwithdrawing substituent in the 2-position lowers the $\mathrm{p} K_{\mathrm{a}}$ of the pyridyl group and therefore its ability to bind to $\mathrm{Rh}$ and interrupt the catalytic cycle. This hypothesis is supported by control experiments where asymmetric coupling of simple boronic acids in the presence of pyridine completely shuts down the reaction, but addition of 2-Cl-pyridine had no inhibitory effect.

The presence of equimolar amounts of water was found to improve results in some examples. NMR spectroscopic studies suggest that water disassembles aggregate boroxines, releasing the corresponding boronic acid. The presence of water might also help to regenerate $L^{*} \mathrm{RhOH}$ during the catalytic cycle.

\section{Mechanism}

A mechanism consistent with our current understanding of the reaction is shown in Figure 8 (right). Initially the $L^{*} \mathrm{RhOH}$ complex reacts with the boronic acid to give an $\mathrm{Rh}-\mathrm{Ar}$ 
intermediate. Oxidative addition with the racemic allyl halide then gives $\mathrm{Rh}$ (III) complexes. These allyl species may equilibrate via suprafacial 1,3-isomerisation and reductive elimination is proposed to be the rate- and enantiodetermining step of the cycle.

\section{Piperidene substrates}

Piperidine and its derivatives are privileged structural motifs in bioactive compounds and drugs. ${ }^{96}$ Cross-coupling reactions for the synthesis of enantioenriched (dehydro)piperidine products are rare and relevant examples are either limited to the $\alpha$ position or enantiospecific couplings. ${ }^{97,98}$ We found that $N$-Boc protected piperidinyl chloride was suitable for this reaction and the protecting group could be easily removed after coupling. In this case $\mathrm{Cl}-\mathrm{MeO}-\mathrm{BIPHEP}$ proved to be the best ligand (Fig. 9a). We also explored the case where both coupling partners were heterocyclic (Fig. 9b). The reaction work well in most cases (91-99\% ee) and provides a variety of structures which would otherwise be difficult to access. It is worth noting that coupling the $N$-Boc pyrrole group occurred with low yield (17\%), probably due to sterics, despite high ee.

a) Cross-coupling with $\mathbf{N}$-heterocyclic piperiden

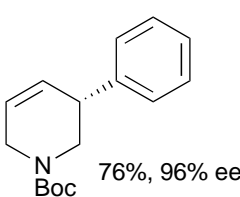<smiles>O=C(O[Na])OC(=O)Oc1ccccc1</smiles><smiles>COc1ccc(-c2ccccc2)c(-c2c(-c3ccccc3)ccc(Cl)c2OC)c1OC(F)F</smiles><smiles>Oc1cccc(CC=CI)c1</smiles><smiles>O=[R6]c1ccccc1</smiles><smiles>O=C(O)OCc1ccccc1</smiles>

Boc $\mathrm{H}: 72 \%, 94 \%$ ee

$86 \%, 96 \%$ ee

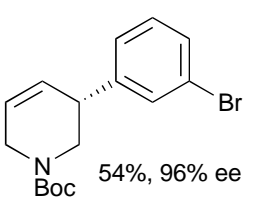

$\mathrm{R}=\mathrm{Me}: 79 \%, 96 \%$ ee

b) Heterocyclic cross-coupling<smiles>CC(C)(C)O[Mg]OC(=O)OCc1ccco1</smiles><smiles>O=[R6]C1CNCC=C[C@@H]1c1ccsc1</smiles><smiles>O=C(O)C1CNCC=C[C@@H]1c1cc2ccccc2o1</smiles><smiles>O=C(O)OC(=O)OCc1ccccc1</smiles>

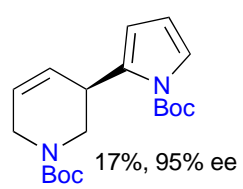

Figure 9 Selected examples for the Rh-catalyzed asymmetric allylic arylation and heterocyclic cross-coupling.

\section{Applications}

Many single enantiomer drugs are synthesized as racemic mixtures and subsequently separated via chromatographic

processes to provide both enantiomers. ${ }^{99,100}$ However, this becomes unsuitable for large-scale preparations because the undesired enantiomer normally has to be discarded. As seen below, we have demonstrated that this asymmetric coupling chemistry can be used in the synthesis of natural products and drugs.

Isoanabasine is a natural alkaloid resembling common central nervous system activators. The natural product features two medicinally important $\mathrm{N}$-heterocyclic rings, and pyridyl piperidines are reported to have therapeutic potential due to their activity as nicotinic acetylcholine receptors. ${ }^{101}$ To our knowledge, the only previous 'asymmetric synthesis' of isoanabasine involved resolution of racemic material using stoichiometric BINOL and multiple recrystalizations. ${ }^{102,103}$ By means of our asymmetric Suzuki-Miyaura coupling (+)isoanabasine was synthesized with $95 \%$ ee (Scheme 12a). After the asymmetric coupling ( $40 \%$ yield), hydrogenation of the double bond was carried out using Wilkinson's catalyst to avoid epimerization of the chiral centre. $\mathrm{Pd}$ mediated hydrogenation of the $\mathrm{C}-\mathrm{Cl}$ bond and Boc-deprotection (38\% over three manipulations) then gave $(+)$-isoanabasine with $95 \%$ ee. Although we have not done so, we suspect that the 2 $\mathrm{Cl}$-pyridine intermediate in our synthesis could be used to generate compound libraries.

We then sought to synthesize the antipsychotic drug (-)preclamol,104,105 a potent dopamine receptor agonist. Preclamol's asymmetric synthesis has been recently described via other powerful transformations. ${ }^{65,106}$ Using the chemistry developed here, two related coupling routes gave preclamol with high ee (>94\% ee) from 3-hydroxyphenyl- or 3methoxyphenylboronic acid starting materials (Scheme 12b).

a) Synthesis of isoanabasine

b) Two synthetic routes to preclamol

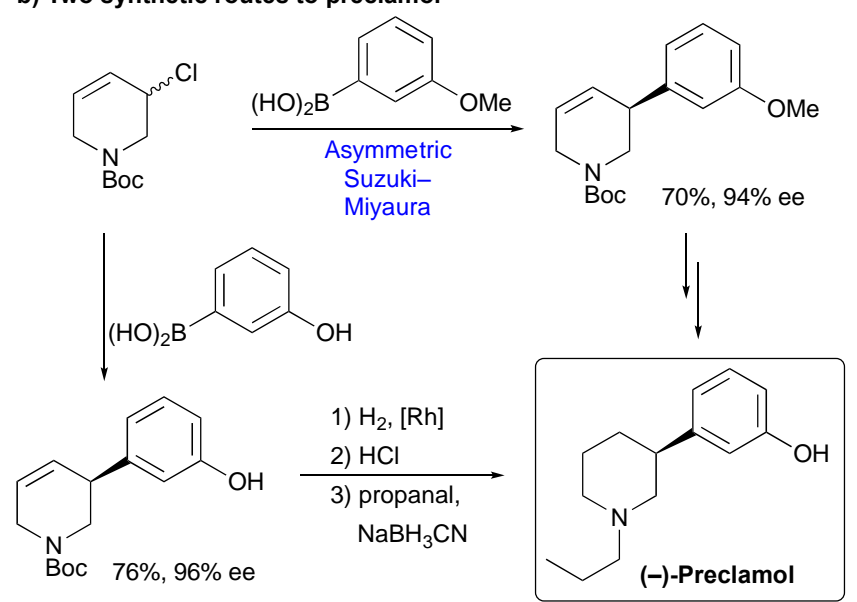

Scheme 12 Applications of the Rh-catalyzed asymmetric allylic alkylation to the syntheses of isoanabasine and preclamol. 
Niraparib (Zejula) has been recently FDA approved for the maintenance treatment of certain recurrent cancers. The compound is a PARP inhibitor which is currently the subject of several additional clinical trials for various cancers including those of the ovary, lung, breast, and prostate. ${ }^{107}$ The originally published process route to niraparib details the struggle to obtain suitable piperidine intermediates in optically pure form. While it was possible to separate the enantiomers of some piperidines using resolution, successful chromatographic methods proved difficult to scale up (Scheme 13a, left). ${ }^{108}$ In a subsequent publication Merck describes an enzymatic desymmetrization approach from a racemizable chiral aldehyde, which provides a novel solution to accessing enantiomerically pure 3-substituted piperidines via lactam intermediates (Scheme 13a, right). ${ }^{109}$

The well-documented difficulties in obtaining niraparib in enantiomerically pure form inspired us to study of a SuzukiMiyaura strategy with a key asymmetric $\mathrm{C}-\mathrm{C}$ bond-forming step. Ultimately, three different syntheses of niraparib were developed (Scheme 13b). Each of the routes is reasonably short and conceptually straightforward, clearly demonstrating the flexibility and power of the method.
The first synthesis uses 4-nitrobenzeneboronic acid in the coupling (64\%, $94 \%$ ee). To test the robustness of the method we performed a larger-scale reaction to give 3.4 grams of product. Two-stage reduction, first using Wilkinson's catalyst to hydrogenate the double bond, then Pd/C catalyzed nitroreduction, intercepted an enantioenriched compound used in Merck's first generation process. Another route involves asymmetric coupling with 4-bromobenzeneboronic acid, which provides a heterocycle $(97 \%, 95 \%$ ee) that can easily be hydrogenated to a key intermediate in Merck's secondgeneration synthesis.

We also developed a more convergent route that relies on a complex boronic acid coupling partner. Access to the phenylated $2 \mathrm{H}$-indazole boronic acid was problematic (it is likely unstable) so a pinacol boronic ester was used instead. The cross-coupling gave the desired piperidine with high yield and enantioselectivity $(94 \%, 98 \%$ ee) and we scaled this procedure up to obtain $1.5 \mathrm{~g}$ of alkylation product. After hydrogenation, a late stage niraparib intermediate was obtained.

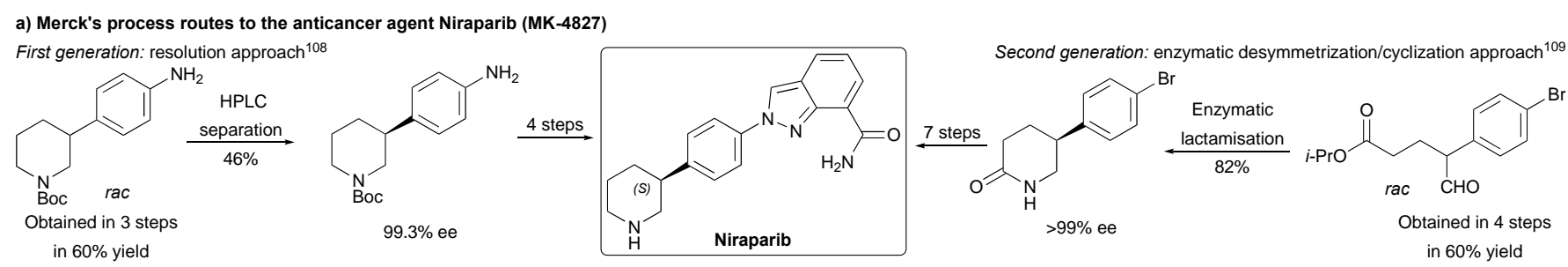

b) Three asymmetric Suzuki-Miyaura based approaches to Niraparib
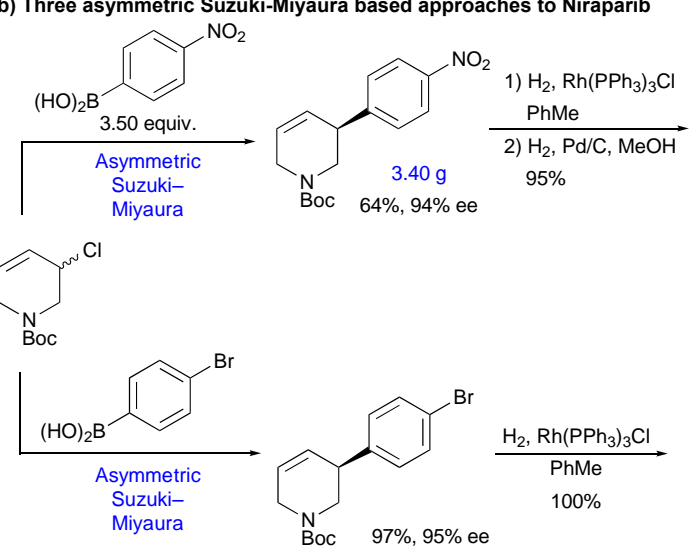
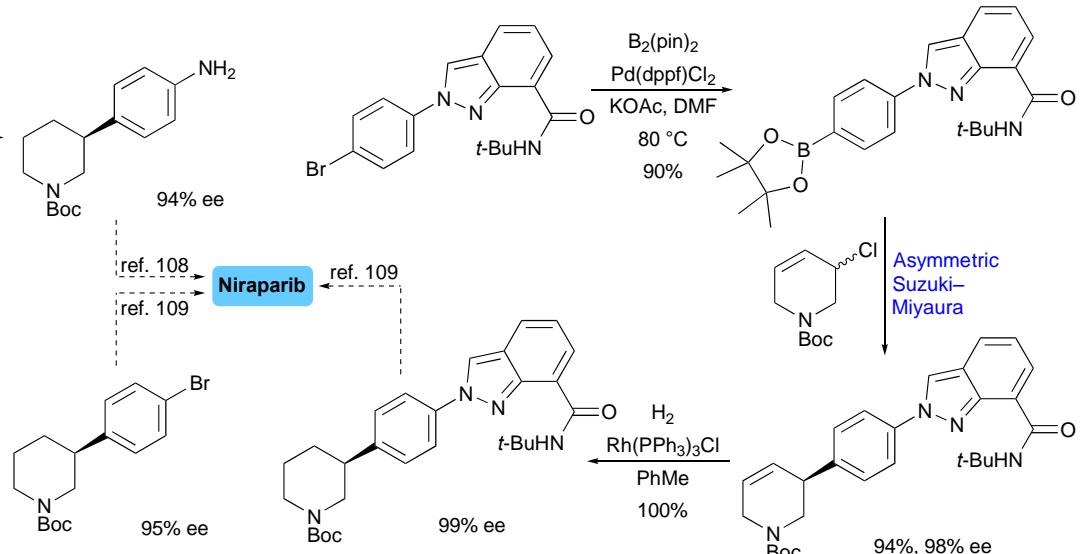

Scheme 13 a) Previously reported process chemistry routes to Niraparib (Zejula); b) Enantioselective Suzuki-Miyaura approaches developed by our group.

\section{Conclusions}

Asymmetric $\mathrm{C}-\mathrm{C}$ bond formation allows access to enantioenriched building blocks, which are essential for the syntheses of bioactive molecules and drugs. While enantiospecific transformations and additions to prochiral molecules are already important tools, the use of racemic starting materials in asymmetric cross-coupling reactions with non-stabilized nucleophiles is not well established, despite tremendous potential.

Asymmetric $\mathrm{Csp}^{3}-\mathrm{Csp}^{3}$ coupling can be achieved using copper catalysis in combination with alkyl zirconium reagents. Mechanistic studies reveal complex dynamic kinetic processes at play here, where the $\mathrm{Cu}$-catalyst racemizes the allyl chloride and selects one enantiomer for highly enantioselective addition. While the method allows rapid access to a variety of enantiopure molecules that would be difficult to make in other 
ways, we found that attempts to induce this mechanistic pathway in different reactions was challenging.

Remarkably, although we were successful in developing other highly enantioselective additions to racemates, they appear to operate via completely different mechanisms. The combination of Rh-catalysis and arylboronic acids with cyclic racemic halides was found to be highly enantioselective. These asymmetric Suzuki-Miyaura type couplings are robust and have now been applied to vinyl- and heteroarylboronic acids with a variety of cyclic electrophiles, so that even two heterocyclic molecules can be asymmetrically coupled. The method has been used in asymmetric syntheses of the natural product isoanabasine, the drug preclamol, and in three syntheses of the anticancer PARP inhibitor Niraparib (Zejula).

We envisage that when asymmetric coupling reactions with racemic starting materials are more fully developed they will become widely used in asymmetric catalysis and target synthesis. There are still significant limitations to the coupling partners that can be used with these methods, most notably the necessity to use cyclic allylic (pseudo)halides. Mechanistic studies are crucial to further developing this chemistry, as it is through the understanding of the mechanism that current limitations and potential can be realized, and new strategies and targets imagined.

\section{Acknowledgements}

We thank the EPSRC (EP/N022246/1) for generous support of this research effort. P.S. and T.P. thank the People Programme (Marie Curie Actions) of the European Union's Seventh Framework Programme (FP7/2007-2013) under REA grant agreement 316955 for funding.

\section{References}

1

2

3

4

5

6

7

10 K. Geurts, S. P. Fletcher, A. W. van Zijl, A. J. Minnaard and

B. L. Feringa, Pure Appl. Chem., 2008, 80, 1025.

11 Z. Lu and S. Ma, Angew. Chemie Int. Ed., 2008, 47, 258.

12 N. A. Butt and W. Zhang, Chem. Soc. Rev., 2015, 44, 7929.

13 B. M. Trost, Tetrahedron, 2015, 71, 5708.

14 N. Miyaura, K. Yamada and A. Suzuki, Tetrahedron Lett.,
1979, 20, 3437.

B. W. Glasspoole, E. C. Keske and C. M. Crudden, in New Trends in Cross-Coupling: Theory and Applications, 2014, pp. 521-550.

S.-M. Zhou, M.-Z. Deng, L.-J. Xia and M.-H. Tang, Angew. Chem. Int. Ed., 1998, 37, 2845.

D. Imao, B. W. Glasspoole, V. S. Laberge and C. M. Crudden, J. Am. Chem. Soc., 2009, 131, 5024.

T. Ohmura, T. Awano and M. Suginome, J. Am. Chem. Soc., 2010, 132, 13191.

J. C. H. Lee, R. McDonald and D. G. Hall, Nat. Chem., 2011, 3, 894 .

G. A. Molander and S. R. Wisniewski, J. Am. Chem. Soc., 2012, 134, 16856.

N. Rodríguez, C. Ramírez de Arellano, G. Asensio and M. Medio-Simón, Chem. - A Eur. J., 2007, 13, 4223.

A. He and J. R. Falck, J. Am. Chem. Soc., 2010, 132, 2524.

B. J. Stokes, S. M. Opra and M. S. Sigman, J. Am. Chem. Soc., 2012, 134, 11408.

A. N. Cammidge and K. V. L. Crépy, Chem. Commun., 2000, 1723.

J. Yin and S. L. Buchwald, J. Am. Chem. Soc., 2000, 122, 12051.

A. Ros, B. Estepa, P. Ramírez-López, E. Álvarez, R. Fernández and J. M. Lassaletta, J. Am. Chem. Soc., 2013, 135, 15730.

D. Zhang and Q. Wang, Coord. Chem. Rev., 2015, 286, 1. X.-P. Zeng, Z.-Y. Cao, Y.-H. Wang, F. Zhou and J. Zhou, Chem. Rev., 2016, 116, 7330.

M. C. Willis, L. H. W. Powell, C. K. Claverie and S. J. Watson, Angew. Chemie Int. Ed., 2004, 43, 1249.

S. J. Byrne, A. J. Fletcher, P. Hebeisen and M. C. Willis, Org. Biomol. Chem., 2010, 8, 758.

F. Menard, T. M. Chapman, C. Dockendorff and M. Lautens, Org. Lett., 2006, 8, 4569.

F. Menard, D. Perez, D. Sustac Roman, T. M. Chapman and M. Lautens, J. Org. Chem., 2010, 75, 4056.

M. Lautens, K. Fagnou and S. Hiebert, Acc. Chem. Res., 2003, 36, 48.

C. C. J. Loh, X. Fang, B. Peters and M. Lautens, Chem. - A Eur. J., 2015, 21, 13883.

P. M. Lundin and G. C. Fu, J. Am. Chem. Soc., 2010, 132, 11027.

Z. Lu, A. Wilsily and G. C. Fu, J. Am. Chem. Soc., 2011, 133, 8154.

S. L. Zultanski and G. C. Fu, J. Am. Chem. Soc., 2011, 133, 15362.

Z. Zuo, H. Cong, W. Li, J. Choi, G. C. Fu and D. W. C. MacMillan, J. Am. Chem. Soc., 2016, 138, 1832.

E. L. Eliel, S. H. Wilen and L. N. Mander, in Stereochemistry of Organic Compounds, Wiley, 1994, pp. 297-464.

J. Jacques, A. Collet and S. H. Wilen, Enantiomers, racemates, and resolutions, Krieger Pub. Co., Malabar, Fla., 1994.

H. Lorenz and A. Seidel-Morgenstern, Angew. Chemie Int. Ed., 2014, 53, 1218.

R. M. Kellogg, Acc. Chem. Res., 2017, 50, 905. 
S. M. Morrow, A. J. Bissette and S. P. Fletcher, Nat. Nanotechnol., 2017, 12, 410. A. Tai, H. Watanabe and T. Harada, Bull. Chem. Soc. Jpn., 1979, 52, 1468.

Rev., 2001, 30, 321.

46 K. Faber, Chem. - A Eur. J., 2001, 7, 5004.

47 H. Ito, S. Kunii and M. Sawamura, Nat. Chem., 2010, 2, 972.

48 J. M. Keith, J. F. Larrow and E. N. Jacobsen, Adv. Synth. Catal., 2001, 343, 5. B. M. Trost and F. D. Toste, J. Am. Chem. Soc., 1999, 121 3543.

E. Vedejs and M. Jure, Angew. Chemie Int. Ed., 2005, 44, 3974. B. M. Trost and D. R. Fandrick, Aldrichimica Acta, 2007, 40, 59. J. T. Mohr, D. C. Behenna, A. M. Harned and B. M. Stoltz, Angew. Chem. Int. Ed., 2005, 44, 6924. V. Bhat, E. R. Welin, X. Guo and B. M. Stoltz, Chem. Rev., 2017, 117, 4528.

395.
395. 427.

R. L. Grange, E. A. Clizbe and P. A. Evans, Synth., 2016, 48, 2911.

B. M. Trost and F. D. Toste, J. Am. Chem. Soc., 1999, 121, 4545.

\section{Res., 2006, 39, 747.}

B. M. Trost and R. C. Bunt, J. Am. Chem. Soc., 1994, 116, 4089.

B. M. Trost, R. Radinov and E. M. Grenzer, J. Am. Chem. Soc., 1997, 119, 7879.

D. L. Hughes, M. Palucki, N. Yasuda, R. A. Reamer and P. J. Reider, J. Org. Chem., 2002, 67, 2762.

B. M. Trost, Org. Process Res. Dev., 2012, 16, 185.

J. P. Janssen and G. Helmchen, Tetrahedron Lett., 1997, 38, 8025.

L. M. Stanley, C. Bai, M. Ueda and J. F. Hartwig, J. Am. Chem. Soc., 2010, 132, 8918.

J. Y. Hamilton, D. Sarlah and E. M. Carreira, Angew. Chemie Int. Ed., 2015, 54, 7644.

B. M. Trost and D. A. Thaisrivongs, J. Am. Chem. Soc., 2008, 130, 14092.

B. M. Trost and D. A. Thaisrivongs, J. Am. Chem. Soc., 2009 131, 12056.

B. M. Trost, D. A. Thaisrivongs and J. Hartwig, J. Am. Chem. Soc., 2011, 133, 12439.

S. R. Harutyunyan, T. den Hartog, K. Geurts, A. J. Minnaard and B. L. Feringa, Chem. Rev., 2008, 108, 2824.

A. Alexakis, J.-E. Bäckvall, N. Krause, O. Pàmies and M. Diéguez, Chem. Rev., 2008, 108, 2796.

J.-B. Langlois and A. Alexakis, in Transition Metal Catalyzed Enantioselective Allylic Substitution in Organic Synthesis, ed. U. Kazmaier, Springer Berlin Heidelberg, 2012, pp. 235268.
J.-B. Langlois and A. Alexakis, Adv. Synth. Catal., 2010, 352, 447.

J.-B. Langlois, D. Emery, J. Mareda and A. Alexakis, Chem. Sci., 2012, 3, 1062.

R. M. Maksymowicz, P. M. C. Roth and S. P. Fletcher, Nat. Chem., 2012, 4, 649.

R. M. Maksymowicz, A. J. Bissette and S. P. Fletcher, Chem. - A Eur. J., 2015, 21, 5668.

Z. Gao and S. P. Fletcher, Chem. Sci., 2017, 8, 641.

M. Sidera, P. M. C. Roth, R. M. Maksymowicz and S. P. Fletcher, Angew. Chem. Int. Ed., 2013, 52, 7995.

H. You, E. Rideau, M. Sidera and S. P. Fletcher, Nature, 2015, 517, 351.

J. F. Teichert and B. L. Feringa, Angew. Chem. Int. Ed., 2010, 49, 2486.

E. Rideau and S. P. Fletcher, Beilstein J. Org. Chem., 2015, 11, 2435.

1 E. Rideau, H. You, M. Sidera, T. D. W. Claridge and S. P. Fletcher, J. Am. Chem. Soc., 2017, 139, 5614.

M. Sidera and S. P. Fletcher, Chem. Commun., 2015, 51, 5044.

T. Hayashi and K. Yamasaki, Chem. Rev., 2003, 103, 2829.

D. K. Leahy and P. A. Evans, in Modern Rhodium-Catalyzed Organic Reactions, Wiley-VCH Verlag GmbH \& Co. KGaA, Weinheim, FRG, 2005, pp. 191-214. T. B. Wright and P. A. Evans, J. Am. Chem. Soc., 2016, 138, 15303.

T. W. J. Cooper, I. B. Campbell and S. J. F. Macdonald, Angew. Chemie Int. Ed., 2010, 49, 8082. S. D. Roughley and A. M. Jordan, J. Med. Chem., 2011, 54, 3451. P. A. Clemons, N. E. Bodycombe, H. A. Carrinski, J. A. Wilson, A. F. Shamji, B. K. Wagner, A. N. Koehler and S. L. Schreiber, Proc. Natl. Acad. Sci., 2010, 107, 18787. M. Sidera and S. P. Fletcher, Nat. Chem., 2015, 7, 935. P. Schäfer, T. Palacin, M. Sidera and S. P. Fletcher, Nat. Commun., 2017, 8, 15762.

R. D. Taylor, M. MacCoss and A. D. G. Lawson, J. Med. Chem., 2014, 57, 5845. J. Almond-Thynne, D. C. Blakemore, D. C. Pryde and A. C. Spivey, Chem. Sci., 2017, 8, 40. P. A. Cox, A. G. Leach, A. D. Campbell and G. C. Lloyd-Jones, J. Am. Chem. Soc., 2016, 138, 9145.

F. Albrecht, O. Sowada, M. Fistikci and M. M. K. Boysen, Org. Lett., 2014, 16, 5212. E. Vitaku, D. T. Smith and J. T. Njardarson, J. Med. Chem., 2014, 57, 10257. T. K. Beng and R. E. Gawley, Org. Lett., 2011, 13, 394. J. Ding, T. Rybak and D. G. Hall, Nat. Commun., 2014, 5, 5474.

S. Andersson and S. G. Allenmark, J. Biochem. Biophys. Methods, 2002, 54, 11. H. Leek and S. Andersson, Molecules, 2017, 22, 158.

101 F. Zheng, X. Du, T.-H. Chou, A. P. Robertson, E. W. Yu, B. VanVeller and R. J. Martin, Int. J. Parasitol. Drugs Drug Resist., 2017, 7, 12. 
102 C.-Q. Kang, Y.-Q. Cheng, H.-Q. Guo, X.-P. Qiu and L.-X. Gao, Tetrahedron: Asymmetry, 2005, 16, 2141.

103 C.-Q. Kang, H.-Q. Guo, X.-P. Qiu, X.-L. Bai, H.-B. Yao and L.X. Gao, Magn. Reson. Chem., 2006, 44, 20.

104 H. Wikstroem, D. Sanchez, P. Lindberg, U. Hacksell, L. E. Arvidsson, A. M. Johnsson, S. O. Thorberg, J. L. G. Nilsson and K. Svensson, J. Med. Chem., 1984, 27, 1030.

105 M. Macchia, L. Cervetto, G. C. Demontis, B. Longoni, F. Minutolo, E. Orlandini, G. Ortore, C. Papi, A. Sbrana and B. Macchia, J. Med. Chem., 2003, 46, 161.

106 T. Jia, P. Cao, B. Wang, Y. Lou, X. Yin, M. Wang and J. Liao, J. Am. Chem. Soc., 2015, 137, 13760.

107 Clinical Trials of Niraparib, https://clinicaltrials.gov/ct2/results?term=niraparib\&amp; Search=Search, (accessed 5 September 2017).

108 D. J. Wallace, C. A. Baxter, K. J. M. Brands, N. Bremeyer, S. E. Brewer, R. Desmond, K. M. Emerson, J. Foley, P. Fernandez, W. Hu, S. P. Keen, P. Mullens, D. Muzzio, P. Sajonz, L. Tan, R. D. Wilson, G. G. Zhou and G. G. Zhou, Org Process Res. Dev., 2011, 15, 831.

109 C. K. Chung, P. G. Bulger, B. Kosjek, K. M. Belyk, N. Rivera, M. E. Scott, G. R. Humphrey, J. Limanto, D. C. Bachert and K. M. Emerson, Org. Process Res. Dev., 2014, 18, 215. 